\title{
The Flow of Information in English and Persian Academic Texts
}

\author{
Mohsen Khedri \\ University Putra Malaysia, Malaysia \\ Email: Khedri295@yahoo.com \\ Seyed Foad Ebrahimi \\ Department of English, Shadegan Branch, Islamic Azad University, Shadegan, Iran \\ Email: Seyedfoade@yahoo.com
}

\begin{abstract}
The present paper focused on the status of thematic progression patterns in academic texts between English and Persian languages. To this end, following McCabe (1999) and North (2005), the first three pages of the first chapter of 8 books in terms of Linguistics (4 in English, as source texts and 4 in Persian, as translated texts) were selected and analyzed regarding thematic progression patterns. The obtained results showed that there were significant differences between the languages in focus concerning how information are introduced in texts especially in case of linear and constant patterns. The main concluding remark taken from this study is that not only authors but also translators should be vigilant of such cohesive devices as thematic progression in creating more cohesive text since, as Hatim and Mason (1990) mentions, we know little about what patterns there are and how equivalence could be achieved between different languages. This is an aspect of texture which should be of crucial importance to the translator (p. 220).
\end{abstract}

Index Terms - theme, rheme, thematic progression, translation

\section{INTRODUCTION}

Indeed, one way of achieving cohesion in text and even translated texts is through thematic patterning, which involves the relationship between clauses based on the information contained in their theme (Belmonte \& McCabe, 1998). Ventola (1995) states that there is no question about the usefulness of the analytical devices --thematic structures-- for applied linguistics, but these tools are not expected to function in the same way in various languages. Contrastive linguistics has paid some attention to these differences. But an area that is relatively unexplored is what happens to the texts' thematic progression when the text goes through a translation process (p. 85).

She adds that sometimes readers may find texts fuzzy since they consider some odd thematic structures that are not typical of the target language. The fault in these texts is very often placed on the author's failures of argumentation and rhetorical skills; it is presumed that the author's logic is not functioning well and his/her argumentation and rhetorics are seen to fail. But often the original argumentation is clear and well-structured rhetorically in the source text; it is the translation that fails and distorts the argumentative and rhetorical patterns (p. 91).

This area is a fruitful one if investigated extensively. Ventola (1995) suggests that "what is needed by is a more thorough investigation of the theme/rheme issues and the role they play in creating textuality and cohesion in translation of texts" (p. 102).

Newmark (1988) argues that a quick glance in fairly recent handbooks on translation theory shows that thematic progression issues are not extensively covered. The focus tends to be on a clause, not on the textual motivation for thematic patterning (p. 60).

Taking thematic progression into account, Baker (1992 as cited in Munday, 2001) points out that translators are forced with two possibilities. The first one is, if the elements placed in thematic position in the source text can easily be placed in theme position in the target language, then the method of development of the two texts will be the same. The second possibility says, if the thematic patterning of the source text cannot easily and naturally be accommodated in the theme, then the translator must abandon it, bearing in mind that the target version should have a method of development and continuity in its own right. Therefore, one of the main flaws that inexperienced translators make is trying to impose the thematic patterning of one language on the structure of the other (128).

She also asserts that thematic structures are realized differently in different languages. She emphasizes that, as with the thematic structure, density and progression of cohesive ties play an important role throughout a text. This web of relationships may have to differ between source text and target text because of the different networks of lexical cohesion across languages (p. 97).

In agreement with Baker's (1992) viewpoint, Hatim and Mason (1990) mention that there is a need for analysis of thematic progression in different languages over a range of text types. We know little about what patterns there are and how equivalence could be achieved between them. This is an aspect of texture which should be of crucial importance to 
the translator (p. 220).

Furthermore, Fries (1995) also states that systemic theory predicts that every language will have some grammatical function which serves to mark the point of departure for the clause (or other grammatical units) as message. Moreover, one would predict that although there will be a general similarity across languages in the functions of thematic material, the specific uses to which that material is put in the various languages of the world will differ (p. 1).

Also, Ventola (1995) mentions that the translation choices by translator do not follow and display the same rhetorical principles and effects as the author's original text. The translator changes the thematic structure of the clauses. Consequently, he/she will succeed, to some extent, in displaying the unfolding of the global structure of the text in the translated version (p. 98).

The notion of thematicity in translation has been discussed widely in linguistic literature, especially within Prague School of linguistics and systemic-functional theory. Various scholars have in recent years contributed to the study of textuality of texts by analyzing their theme, thematic structure, and thematic progression in text across different languages (Belmonte \& McCabe, 2001; Green, et al 2000; Jia-po \& Bin, 2006; Khedri, 2008; McCabe, 1999; Ventola, 1995; Williams; 2005) to find out how academic texts unfold thematically.

Ventola (1995) carried out a study in which she compared the role of thematic structure in German philosophy texts produced by German authors and their parallel texts in English, their translation. McCabe (1999) compared the thematic patterning in both English and Spanish history textbooks. Williams (2005) performed the analysis of thematic items referring to research and researchers in the discussion section of Spanish Biomedical articles and English-Spanish translation. And applying Halliday's (1994) thematic organization and McCabe's (1999) thematic progression, Khedri (2008) scrutinized thematic development and progression in English academic texts and their translations in Persian.

In one extreme, taking the importance of thematic progression patterning in creating a more cohesive text into account, it requires shedding more light on the role of thematic progression patterns, but in translation. This means that to see what happens to them and how they are tackled by translators when the text goes through a translation process. And in the other extreme, even though many studies have been done on the role and function of thematicity in translation, work on the status of theme between/among different languages is still extremely low. The gap is felt more when this scarcity comes to the status of thematic progression in English and Persian languages. Therefore, this study aims at scrutinizing how patterns are thematically progressed in English academic texts and their parallel in Persian.

\section{METHODOLOGY}

\section{A. Unit of Analysis}

Different researchers have selected different grammatical units to study theme, according to their purposes. For Halliday, the basic unit for thematic analysis is the clause, for Whittaker, orthographic sentences, for McCabe, independent conjoinable clause complex or T-unit. For the purpose of this research, the T-unit was adopted as the unit of analysis. Fries (1994) defined T-unit as "an independent clause together with all hypotactically related clauses which are dependent on it" (p. 229).

To Fries and Francis (1992 as cited in North, 2005, p. 6), analyzing theme at the level of the T-unit rather than the individual clause makes it easier to focus on patterns of thematic development in a large amount of text, and can also be justified on the grounds that the thematic structure of a dependant clause is often constrained by comparing features. Following McCabe (1999), in order to make the analysis possible, the researcher adopted T-unit as the unit of analysis since as McCabe (1999) mentions, it is recognized as optimal unit for textual analysis regarding thematic progression (p. 73).

\section{B. Text Selection}

The corpus used in this study limited to sample academic texts that were selected from the first three pages of the first chapters of 8 linguistics books (4 in English and 4 in Persian). The selection was done with the aim of building a corpus representative of linguistics books taught in the Iranian universities at BA and MA levels and translated into Persian. The corpus was divided into two subcorpora: sample academic texts in English and sample academic texts in Persian. The Persian texts were the translated versions of the same English texts. The obtained corpus contained 9955 words (4802 for English and 5153 for Persian). There were some reasons behind this selection. The first reason was that the first chapter of a book is usually its point of departure. The second one was to maintain the consistency of thematic progression among paragraphs in each text and avoid invalid judgment of thematicity. The third reason was that the texts chosen represented a variety of authors and translators. And the last one was, it appeared that this quantity was enough to allow the researcher to arrive at valid generalizations.

\section{Instruments}

In order to achieve a well-organized study, complete models are required for analyzing the data. The theoretical framework was the revised Danes' (1974) model of thematic progression patterns suggested by McCabe (1999) and used for determining thematic progression. The practical frameworks to analyze the data were those proposed by McCabe (1999) and North (2005).

Danes (1974, as cited in Downing, 2001, p. 5) proposed a number of thematic progression patterns that manifest 
differently in different genres as follows: linear pattern, constant pattern (or thematic iteration), split rheme, and split theme pattern.

1. Linear pattern: Danes (1974, as cited in Downing, 2001, p. 5) refers to this as the most elementary or basic thematic progression pattern, where the item in the rheme of the first clause becomes the theme of the subsequent clause.

2. Constant pattern: In this pattern, the item in the theme of the first clause is also selected as the theme of the following clause, though not necessarily with identical wording.

3. Split rhematic pattern: In this pattern, the rheme of the first clause is split into two items, each in turn being taken as a theme element in subsequent clauses.

4. Split theme pattern: To Danes's patterns of thematic progression one has been added. In this kind of thematic progression which was proposed by McCabe (1999, p. 175), the theme of the first clause is split into two or more ideas, and these ideas are developed in the themes of subsequent clauses.

Adopting the Danes' thematic progression patterns, McCabe (1999, p. 176) considered a revised model of Danes' thematic progression patterns. She categorized these patterns into 2 overall types: a) theme progression including constant theme and split theme and b) rheme progression including simple linear and split rheme. McCabe (1999) did not consider derived theme as a different sort of thematic progression, since it may be related to proceeding themes and rhemes through some types of inference involved in simple linear or constant theme (p. 171). According to McCabe (1999), there are a rather large percentage of clauses which do not fit into any of the patterns proposed by Danes, since it appears that Danes employed a standard for theme specification which accords more with the notion of "given". Therefore, it is necessary to modify Danes' model in order to apply it in other analyses which use a different standard for theme specification (p. 270). What's more is that, Danes' model was only tested on English texts and a few other languages. So, more evidence is needed from other languages to see whether other systematic patterns emerge in texts in other languages.

The major rationale behind the selection of the above models was twofold: 1) As Martinez (2003, p. 108) mentions, these models provide plausible and attestable mechanisms for determining the thematic structures of the texts correctly; 2) They are practical, reliable, and up-to-date models. Most of the studies that have been done in terms of thematic analysis have resorted to these models.

\section{Procedure}

The procedure applied in this study was firstly, the selection of sample texts from the first three pages of the first chapters of 8 linguistics books. These sample texts were in English and their translations in Persian. Secondly, the texts, both original and translated versions, were compared and contrasted according to the above mentioned models to determine their thematic progression patterns. Finally, the data was analyzed to scrutinize the possible similarities and differences that would exist in English and Persian languages in terms of thematic progression.

One problem with textual analysis of texts is that there is always the danger of making mistakes in interpretation. To avoid the threat of reliability in the analysis, the first three pages of two applied linguistics books in both languages from the corpus were also analyzed by an experienced researcher in applied linguistics field and agreement was made on the method of analysis.

\section{E. Data Analysis}

To analyze the texts in the present study quantitatively, the frequency of different patterns of thematic progression was calculated. Next, Chi-square as a significance test was employed to compare and contrast the obtained frequencies to see the statistically significant differences. In sum, the data were analyzed using the statistics software SPSS (Statistics Package for Social Sciences).

\section{RESUlT AND DISCUSSION}

The data were analyzed using McCabe (1999) to investigate the different types of thematic progression patterns including linear, constant, split rheme, and split theme This study followed North's (2005) procedure to identify links by looking for the first most constituent that has a topical link with the proceeding main clause. If the left most item identified as a link was a modifier then the whole constituent was examined for link to preceding text.

It deserves to point out that in this study, some T-units were found with no theme in initial position being started by verb. These verb-initial T-units were analyzed and put into simple linear progression chain. Doing so was supported by North (2005). To her, these constructions have come from the previous rhemes, so they have linear progression provided that the subject for the verb is the same and the verbs have the same reflection for the tense.

The other worthy issue is in case of miscellaneous patterns. As mentioned by McCabe (1999), the themes for which the reader has to go back more than three clauses to find previously mentioned concept were not realized as part of thematic progression patterns. So, they were fallen into a separate group namely miscellaneous themes.

The corpus was analyzed to identify the frequency of different patterns of thematic progression. The results are illustrated in the table below. 
TABLE 1.

FREQUENCY ANALYSIS OF THEMATIC PROGRESSION PATTERNS IN ENGLISH AND PERSIAN TEXTS

\begin{tabular}{llllll}
\hline & Linear $(\%)$ & Constant $(\%)$ & Split rheme $(\%)$ & Split theme $(\%)$ & Miscellaneous $(\%)$ \\
\hline English & $104(41.10)$ & $49(19.36)$ & $1(0.41)$ & 0 & $99(39.13)$ \\
Persian & $153(56.66)$ & $25(9.25)$ & $1(0.39)$ & 0 & $91(33.70)$ \\
\hline
\end{tabular}

Based on the results illustrated in table 1, while linear pattern utilized more frequent by translators in target texts, authors in original texts disposed more to use constant pattern. This over-use of constant pattern resulted in texts composed of more simplistic, repetitive, and redundant paragraphs by continuous application of the same topic. In Wang's (2007) mind, constant patterns make a text be more static and also narration and description are featured by constant progression while in an argumentative text the "cross-referential" links from the rheme of one clause to the theme of the next clause affect the dynamicity of the text more (p. 7). Furthermore, in a text in which constant patterns are used frequently, the text often reads like a list with a little development of information presented in the rheme (p. 6).

But, over-using of linear pattern in target texts might reflect the argumentative nature of translated texts and this could be one of Persian propensities. This finding is compatible with McCabe's (1999) results. She declares that in using simple linear pattern, writers can ensure that the readers are constantly "with them" with regards to point of departure, thus elaborating on concepts in a way which allows readers to optimally build up the conceptual framework.

Comparing these two patterns in both text types together, linear (104 cases in English and 153 cases in Persian) outrun constant (49 cases and 25 cases in respective languages). Such a result is the same as what gained by McCabe (1999). She found more linear chains over constant chains in history texts. She related this to the analytical or explicit nature of history texts, and this was because of the pedagogical goal of the texts and asymmetric links between the writer and the reader (p. 23). McCabe (1999) expresses that linear links set up relationships implying cause and effect, develop ideas, and improve cohesion between sentences in a paragraph (p. 211). So, it can be taken out as concluding remark that one of the principles of argumentative texts is the use of linear patterns but in high proportion.

Concerning the other two patterns, split rheme and split theme, the former was underestimated and the latter was neglected by both authors and translators in source and target texts. And, in case of miscellaneous pattern, 99 cases and 91 cases of the total patterns progressed in English and Persian were put in this category. Dealing with miscellaneous pattern, there are contradictory ideas among researchers. Wang (2007) believes that employing miscellaneous pattern leads to creating text which lacks the expansion of discourse (p. 6). Contrary to Wang's (2007), McCabe (1999) asserts that:

In no way are all of the themes in the corpus chained to a previous theme or rheme in close proximity. However, this does not necessarily mean that they are difficult to process, only that they are difficult to analyze in terms of linking them to one previous point in the discourse in order to say that they belong to one or another chain. These themes are important to the organization of the discourse; they are only labeled as peripheral in that they are peripheral to the thematic progression patterns (p. 180).

Patterns that did not fit into any of the thematic progression patterns proposed by McCabe (1999) were categorized into a separate group, namely miscellaneous. Miscellaneous bonds play a key role in information development. Due to the accessibility of their references to the reader, they can equip the text with thematic continuity. Sometimes the reader goes back to more than 3 clauses to link concepts together even though the clauses are far from the thematic rules. Sometimes, based on the contextual clues, context compensates for the distance between the clauses providing the opportunity for the reader to create a relationship between ideas and link them together. And, sometimes a new idea is introduced not connected to the preceding clauses. However, their analyses require great efforts on the part of the readers.

To compare the total frequency of thematic progression patterns in both languages, the Chi-square analysis was applied. The results are showed in the following table.

TABLE 2. CHI-SQUARE ANALYSIS OF THEMATIC PROGRESSION PATTERNS IN ENGLISH AND PERSIAN TEXTS

\begin{tabular}{llllll}
\multicolumn{5}{c}{ CHI-SQUARE } & ANALYSIS OF THEMATIC PROGRESSION PATTERNS IN ENGLISH AND PERSIAN TEXTS \\
\hline Linear & English & Persian & X2 & Df & P \\
Constant & 104 & 153 & 9.342 & 1 & 0.022 \\
Split rheme & 49 & 1 & 7.784 & 1 & 0.053 \\
Split theme & 0 & 0 & 0.000 & 1 & 1.000 \\
Miscellaneous & 99 & 91 & $*$ & $*$ & $*$ \\
\end{tabular}

The result of Chi-square revealed that there were significant differences between English texts and their Persian counterparts in terms of linear and constant patterns.

\section{CONCLUSION}

As gained from this study and to that pointed out by Ventola (1995), the translation choices by translator do not follow and display the same rhetorical principles and effects as the author's original text. The translator changes the thematic structure of the clauses. Consequently, he/she will succeed, to some extent, in displaying the unfolding of the global structure of the text in the translated version (p. 98). As far as significant differences between English academic 
texts and their counterpart in Persian in light of linear and constant patterns shown by the obtained results, at least in this study, it can be concluded that making any unmotivated and unreasonable change into them may cause difficulties in conveying the intended meaning of source text's author and then getting readers into great troubles since thematic progression may be quite different among various languages.

In sum, this study has theoretical and pedagogical implications. From theoretical viewpoint, this study sheds light on the thematic progression in both Persian and English languages which could be eventually useful in understanding the thematic structure of human language. From educational perspective, translators and those who are interested in translation profession can apply the findings of this study in translating any text type from English to Persian. Being conscious of grammatical structure of each language at least at the level of thematization especially thematic progression can be a useful device for selecting suitable theme in initial position and convey the intended message uttered by source texts' writers. All in all, doing so may lead to creating smoother translated texts and also may help the reader to follow the flow of information in a clear way.

\section{REFERENCES}

[1] Belmonte, I. A. \& A. M. McCabe (1998). Theme-rheme patterns in L2 writing. http://www.ucm.es/BUCM/edu/articulos/DIDA.pdf (accessed 30/5/207).

[2] Belmonte, I. A. \& A. M. McCabe (2001). Theme, transitivity and cognitive representation in Spanish and English written texts. http://www.ucm.es/info/circulo/no7/mccabe.htm (accessed16/5/2007).

[3] Downing, A. (2001). Thematic progression as a functional resource in analyzing texts. http://www.ucm.es/info/circulo/no5/downing.htm (accessed 9/7/2007).

[4] Fries, P. H. (1994). On theme, rheme and discourse goals. In M. Coulthard (Ed.), Advances in written text analysis (pp. 229249). London: Routledge.

[5] Fries, P. H. (1995). A personal view on theme. In M. Ghadessy (Ed.), Thematic development in English text (pp. 1-19). London: Pinter.

[6] Green, C. F., E. R. Christopher, J. Lam \& K. Mei (2000). The incidence and effects on the coherence of marked theme in interlanguage texts: a corpus based study. Journal of English for Specific Purposes, 19, 99-113.

[7] Halliday, M. A. k. (1994). An introduction to functional grammar. London: Edward Arnold.

[8] Hatim, B. \& I. Mason (1990). Discourse and the translator. London: Longman.

[9] Jia-po, Y. \& W. Bin (2006). The use of thematic structure theory in translation. Sino-US English Teaching, 3.12, 75-81.

[10] Khedri, M. (2008). Thematization and translation in academic texts: Implications for translation courses. M.A. thesis, Islamic Azad University, Science and Research of Ahvaz.

[11] Martinez, I. A. (2003). Aspects of theme in the method and discussion sections of biology journal article in English. Journal of English for Academic Purpose, 2, 103-123.

[12] McCabe, A. M. (1999). Theme and thematic patterns in Spanish and English history texts. http://www.wagsoft.com/systemics/archive/McCabe.phd (accessed 9/7/2007).

[13] Munday, J. (2001). Introducing translation studies: Theories and applications. London: Routledge.

[14] Newmark, P. (1988). A textbook of translation. NewYork: Prentic Hall.

[15] North, S (2005). Disciplinary variation in the use of theme in undergraduate essays. Journal of Applied Linguistics, 26.3, 431452.

[16] Ventola, E. (1995). Thematic development and translation. In M. Ghadessy (Ed.), Thematic development in English text (pp. 85-104). London: Pinter.

[17] Wang, L. (2007). Theme and rheme in the thematic organization of text: Implication for teaching academic writing. Asian EFL Journal, 9.1, 1-11.

[18] Williams, I. A. (2005). Thematic items referring to research and researchers in the discussion section of Spanish biomedical articles and English-Spanish translation. International Journal of Translation, 51.2, 124-160.

Mohsen Khedri is a Ph.D candidate in Applied Comparative Linguistics, Universiti Putra Malaysia (UPM), Malaysia. His main areas of research are genre analysis and discourse studies such as metadiscourse and thematicity. He has published more than ten articles in various internationally refereed journals worldwide.

Seyed Foad Ebrahimi is a lecturer at the department of English, Shadegan Branch, Islamic Azad University, Shadegan, Iran. He is a Ph.D candidate in Applied Comparative Linguistics, Universiti Putra Malaysia (UPM), Malaysia. His main areas of research are genre analysis and discourse studies. 